3. Ng DK, Wong JC, Chan CH, Leung LC, Leung SY. Ambulatory blood pressure before and after adenotonsillectomy in children with obstructive sleep apnea. Sleep Med 2010;11:721-5.

4. $\mathrm{Au}$ CT, Ho CKW, Wing YK, Lam HS, Li AM. Acute and chronic effects of sleep duration on blood pressure. Pediatrics 2014; 133(1):e64-e72.

5. Gupta NR, Kremer TM, Salerno A, Adhami S, Kremer J, Gupta RM. Association of blood pressure and sleep complaints in children evaluated for hypertension by ambulatory blood pressure monitor (ABPM). J Am Soc Nephrol 2012;23:461A. abstract.

DOI: $10.1056 /$ NEJMc1408238

TO THE EDITOR: In her article on pediatric hypertension, Ingelfinger does not mention the role of uric acid and hyperuricemia. Randomized trials have shown the benefits of urate-lowering treatment in lowering blood pressure in adolescents with hyperuricemia and recently diagnosed essential hypertension ${ }^{1}$ and in obese adolescents with prehypertension. ${ }^{2}$ I believe that there is sufficient evidence to support the inclusion of uric acid measurement in the workup for evaluation of adolescents with suspected hypertension and for a trial of allopurinol in those with hyperuricemia.

\section{Gianni Bellomo, M.D.}

Media Valle del Tevere Hospital

Todi, Italy

bellomopg@tin.it

No potential conflict of interest relevant to this letter was reported.

1. Feig DI, Soletsky B, Johnson RJ. Effect of allopurinol on blood pressure of adolescents with newly diagnosed essential hypertension: a randomized trial. JAMA 2008;300:924-32.

2. Soletsky B, Feig DI. Uric acid reduction rectifies prehypertension in obese adolescents. Hypertension 2012;60:1148-56.

DOI: 10.1056/NEJMc1408238

THE AUTHOR REPLIES: Gupta and Gupta point out the importance of sleep-disordered breathing in the pathobiology of adolescent hypertension, though sleep patterns were among the factors mentioned in the article as part of the medical evaluation and nonpharmacologic therapy. In ad- dition to their study, ${ }^{1}$ work from the Tucson Children's Assessment of Sleep Apnea Study has indicated that decreased sleep time and elevated body-mass index are associated with increases in blood-pressure levels. ${ }^{2}$ Best therapy for sleepdisordered breathing in children and adolescents is an evolving area, especially because adherence to CPAP regimens is difficult for children and adolescents, as discussed in a recent review by Tapia and Marcus. ${ }^{3}$

Uric acid, as Bellomo notes, has been evaluated as a biomarker for essential hypertension in children and adolescents. Much data, particularly from animal models, indicate that increases in uric acid lead first to reversible vasoconstrictive changes, mediated by stimulation of renin release and a decrease in the levels of circulating nitrates, and later to a second phase in which changes in the vasculature within the kidney result in sustained blood-pressure elevation and, ultimately, to salt-sensitive hypertension. ${ }^{4}$ Currently, short-term data indicate that the use of allopurinol in children or adolescents with hypertension may be effective, but such studies are preliminary. ${ }^{4}$ Further and longerterm trials would be needed before allopurinol or other therapy to lower uric acid levels in children with hypertension would be recommended.

Julie R. Ingelfinger, M.D.

Since publication of her article, the author reports no further potential conflict of interest.

1. Gupta NR, Kremer TM, Salerno A, Adhami S, Kremer J, Gupta RM. Association of blood pressure and sleep complaints in children evaluated for hypertension by ambulatory blood pressure monitor (ABPM). J Am Soc Nephrol 2012;23:461A. abstract. 2. Archbold KH, Vasquez MM, Goodwin JL, Quan SF. Effects of sleep patterns and obesity on increases in blood pressure in a 5-year period: report from the Tucson Children's Assessment of Sleep Apnea Study. J Pediatr 2012;161:26-30.

3. Tapia IE, Marcus CL. Newer treatment modalities for pediatric obstructive sleep apnea. Paediatr Respir Rev 2013;14:199-203. 4. Yanik M, Feig DI. Serum urate: a biomarker or treatment target in pediatric hypertension? Curr Opin Cardiol 2013;28:433-8.

DOI: $10.1056 / N E J M c 1408238$

\title{
Pregnancy and Infection
}

TO THE EDITOR: Kourtis and colleagues (June 5 issue $)^{1}$ describe the effect of pregnancy on the susceptibility to and severity of infections, but they only briefly mention the human immunodeficiency virus (HIV). This is surprising, given that HIV causes up to $25 \%$ of deaths during pregnancy and the postpartum period in women in sub-Saharan Africa. ${ }^{2}$ Rigorous studies on the interaction between pregnancy and HIV are scarce, but most of the available data suggest that preg- 
nancy does not increase HIV acquisition ${ }^{3}$ or the severity of HIV-related illness. In addition, HIV does not increase the risk of obstetrical complications, with the exception of sepsis. ${ }^{4}$ Whether pregnancy accelerates HIV disease progression is uncertain. Pregnant women tend to have less advanced HIV disease than nonpregnant women, but few studies stratify patients according to the stage of HIV infection at the start of follow-up. A study involving HIV-infected women who were receiving antiretroviral therapy did not show that pregnancy was associated with an increased risk of death. ${ }^{5}$ This finding implies that the HIVattributable mortality among pregnant women is largely coincidental to pregnancy, and there is little reason to discourage healthy HIV-infected women who want to become pregnant from doing so.

Clara Calvert, M.Sc.

Carine Ronsmans, M.D.

London School of Hygiene and Tropical Medicine London, United Kingdom

clara.calvert@Ishtm.ac.uk

No potential conflict of interest relevant to this letter was reported.

1. Kourtis AP, Read JS, Jamieson DJ. Pregnancy and infection. N Engl J Med 2014;370:2211-8.

2. Calvert $\mathrm{C}$, Ronsmans $\mathrm{C}$. The contribution of HIV to pregnancyrelated mortality: a systematic review and meta-analysis. AIDS 2013;27:1631-9.

3. Drake AL, Wagner A, Richardson B, John-Stewart G. Incident HIV during pregnancy and postpartum and risk of mother-tochild HIV transmission: a systematic review and meta-analysis. PLoS Med 2014;11(2):e1001608.

4. Calvert C, Ronsmans C. HIV and the risk of direct obstetric complications: a systematic review and meta-analysis. PLoS One 2013;8(10):e74848.

5. Westreich D, Maskew M, Evans D, Firnhaber C, Majuba P, Sanne I. Incident pregnancy and time to death or AIDS among HIV-positive women receiving antiretroviral therapy. PLoS One 2013;8(3):e58117.

DOI: 10.1056/NEJMc1408436

TO THE EDITOR: Kourtis et al. review specific infections in pregnancy and the available scant evidence of the increased severity of and susceptibility to infections among pregnant women. However, they omit infections caused by two important pathogens that adversely affect the health and treatment outcomes of mothers and children worldwide: Mycobacterium tuberculosis and cytomegalovirus (CMV).

Globally, tuberculosis causes an estimated half-million deaths per year in women, a large proportion of whom are of reproductive age. Although this condition remains underdiagnosed in pregnant women, the incidence of tuberculosis, tuberculosis-associated mortality, and the risk of hospitalization are high among pregnant women. ${ }^{1}$ Clinical observations show that pregnancy may have an effect on the pathogenesis of tuberculosis and increases the maternal risk of M. tuberculosis infection or reactivation of latent tuberculosis. ${ }^{2,3}$

CMV infection is one of the most common viral infections in humans and can remain latent and reactivate under conditions of immunosuppression. ${ }^{4} \mathrm{CMV}$ infections can reactivate in pregnant women and be transmitted to the neonate in utero or through breast milk.

The complex relationships between pregnancyinduced immunologic changes and infection with intracellular pathogens remain to be defined through carefully designed case-controlled studies.

Alimuddin Zumla, M.D.

University College London

London, United Kingdom

a.i.zumla@gmail.com

Matthew Bates, Ph.D.

University Teaching Hospital

Lusaka, Zambia

Markus Maeurer, M.D.

Karolinska Institute

Stockholm, Sweden

No potential conflict of interest relevant to this letter was reported.

1. Bates M, Ahmed Y, Chilukutu L, et al. Use of the Xpert MTB/ RIF assay for diagnosing pulmonary tuberculosis comorbidity and multidrug-resistant TB in obstetrics and gynaecology inpatient wards at the University Teaching Hospital, Lusaka, Zambia. Trop Med Int Health 2013;18:1134-40.

2. Gupta A, Nayak U, Ram M, et al. Postpartum tuberculosis incidence and mortality among HIV-infected women and their infants in Pune, India, 2002-2005. Clin Infect Dis 2007:45:241-9. 3. Mathad JS, Gupta A. Tuberculosis in pregnant and postpartum women: epidemiology, management, and research gaps. Clin Infect Dis 2012;55:1532-49.

4. Mwaanza N, Chilukutu L, Tembo J, et al. High rates of congenital cytomegalovirus infection linked with maternal HIV infection among neonatal admissions at a large referral center in subSaharan Africa. Clin Infect Dis 2014;58:728-35.

DOI: 10.1056/NEJMc1408436

TO THE EDITOR: The review article by Kourtis et al. focuses on the increased seriousness of a number of viral disorders, malaria, coccidioidomycosis, and a single bacterial disorder, listeriosis, during gestation. However, perhaps the most prevalent example of infection-related virulence in pregnancy is the response to severe urinary tract infection and urosepsis. An important part of prenatal care is screening to detect bacteriuria in early pregnancy, and the literature shows that asymptomatic bacteria left untreated can be followed by acute pyelonephritis in about a fourth 
of women in whom bacteriuria is present. ${ }^{1}$ Moreover, as compared with complications in nonpregnant women, this infection in pregnant women can be quite virulent and can be associated with both substantial decreases in the glomerular filtration rate and volume-independent permeability pulmonary edema, which is virtually absent in nonpregnant women. ${ }^{2,3}$

Marshall D. Lindheimer, M.D.

University of Chicago Pritzker School of Medicine

Chicago, IL

mlindhei@medicine.bsd.uchicago.edu

F. Gary Cunningham, M.D.

University of Texas Southwestern Medical Center

Dallas, TX

No potential conflict of interest relevant to this letter was reported.

1. Whalley PJ, Martin FG, Peters PC. Significance of asymptomatic bacteruria during pregnancy. JAMA 1965;193:879-81.

2. Whalley PJ, Cunningham FG, Martin FG. Transient renal dysfunction associated with acute pyelonephritis of pregnancy. Obstet Gynecol 1975;46:174-7.

3. Cunningham FG, Lucas MJ, Hankins GD. Pulmonary injury complicating antepartum pyelonephritis. Am J Obstet Gynecol 1987;156:797-807.

DOI: 10.1056/NEJMc1408436

THE AUTHORS REPLY: We agree with Calvert and Ronsmans that the evidence regarding increased susceptibility to HIV infection during pregnancy, although intriguing, remains inconclusive. ${ }^{1} \mathrm{We}$ also agree that data are lacking to indicate increased severity of HIV infection among pregnant women, and most of the existing data, although imperfect, do not suggest acceleration of HIV disease during pregnancy. ${ }^{1}$

Most of the literature on increased severity of tuberculosis during pregnancy dates from the pre-antibiotic era, and rigorously conducted studies regarding this question in the era of chemotherapy for tuberculosis are scarce. A recent large cohort study involving pregnant women in the United Kingdom showed no increase in the incidence of tuberculosis during pregnancy, but it did show an increased risk during the first 6 months post partum. ${ }^{2}$ We agree with Zumla et al. that well-designed studies to address this question are needed.

Despite the well-recognized and potentially serious outcomes of CMV infection in neonates, data are lacking to support the increased risk of CMV acquisition or CMV severity among pregnant women. Finally, although potentially serious urinary tract infections and pyelonephritis are more common in pregnant women than in nonpregnant women, these risks are largely attributable to mechanical and physiological factors.

Athena P. Kourtis, M.D., Ph.D.

Centers for Disease Control and Prevention

Atlanta, GA

Jennifer S. Read, M.D., M.P.H.

University of California at San Francisco

San Francisco, CA

Denise J. Jamieson, M.D., M.P.H.

Centers for Disease Control and Prevention

Atlanta, GA

Since publication of their article, the authors report no further potential conflict of interest.

1. Sappenfield E, Jamieson DJ, Kourtis AP. Pregnancy and susceptibility to infectious diseases. Infect Dis Obstet Gynecol 2013;2013:752852.

2. Zenner D, Kruijshaar ME, Andrews N, et al. Pregnancy: a risk for developing tuberculosis? A national cohort and selfcontrolled case series study using UK primary care data abstract. Amsterdam: European Respiratory Society, 2011.

DOI: 10.1056/NEJMc1408436

\section{Medicare Readmission Penalties in Detroit}

TO THE EDITOR: In 2013, more than 2200 U.S. hospitals forfeited a total of approximately $\$ 280$ million in Medicare funds because their readmission rates for congestive heart failure, pneumonia, and acute myocardial infarction exceeded expected rates; these readmission penalties were stipulated by the Affordable Care Act. ${ }^{1}$ We evaluated 2013 and 2014 readmission penalties levied against hospitals in Detroit, as compared with penalties assessed against hospitals in other large cities in the East North Central region of the United States (as defined by the U.S. Census), and we correlated this information with censusderived socioeconomic data. ${ }^{2}$ We also compared readmission penalties for hospitals in the large cities with penalties for hospitals in the remainder of the respective state.

With regard to the largest metropolitan areas in each of the five states in the East North Central region, hospitals in Detroit had the highest mean readmission penalties in $2013(0.93 \pm 0.13 \%$ of Medicare payments, $\mathrm{P}<0.05$ for the comparisons with the other metropolitan areas) and in $2014(0.86 \pm 0.19 \%, \mathrm{P}<0.05$ for the comparisons 